\title{
O CARÁTER EDUCATIVO DAS NARRATIVAS ORAIS DOS ANCIÕES DA COMUNIDADE Quilombola MorRinhos/Poconé-MT
}

\author{
Suely Dulce de Castillho \\ Jocimar Jesus CAMPOS \\ Universidade Federal de Mato Grosso (UFMT), \\ Cuiabá, Mato Grosso, Brasil
}

\begin{abstract}
REsUmo: O objetivo deste artigo é estabelecer a relação entre as narrativas orais da comunidade quilombola de Morrinhos, localizada no município de Poconé, Estado de Mato Grosso, e os processos educativos que são construídos por meio delas na ambiência familiar. A metodologia utilizada foi a história oral, e o principal instrumento de coleta de informações foi a entrevista. Teoricamente, o artigo se apoia em Bosi (2004), Vansina (2010), Hampaté Bâ (2010) e Meihy (2014), entre outros. Os resultados apontam que os velhos ainda desempenham função importante na preservação da memória dessa comunidade, contribuindo na (re)construção de significados essenciais para o processo de constituição sociocultural dos sujeitos, mais especificamente, reforçando valores nas crianças e jovens, tais como respeito à natureza e obediência aos mais velhos.
\end{abstract}

Palavras-chave: Educação. Quilombo. Tradição oral. Pedagogia espontânea.

\section{INTRODUÇÃO}

Noutro tempo, lá pelos idos das décadas de 1950 e 1960, quiçá mais recentemente, ainda que menos frequente, quando no tempo de menino/a, nos lugarzinhos pequenos ou mesmo em cidades de mediano porte, em Mato Grosso, notadamente após o jantar, ou no finalzinho da tarde, reuniam-se mãe, 
pai, irmãos, primos, amigos, vizinhos. A eles se juntavam os mais importantes: as avós e os avôs, em frente à casa, embaixo do pé de mangueira, cajueiro, ou simplesmente no terreiro, para contar as histórias de personagens bastante intrigantes, assustadores, ao mesmo tempo fascinantes e pedagógicos, na essência.

O "Homem Lobo", o "Lobisomem", o "Pé de Garrafa", a "Mula sem cabeça”, a "Mulher de Branco", o "Curupira”, o "Minhocão", a "Bola de Fogo", o "Martelinho de Ouro", e outras tantas narrativas, povoavam as memórias e as lembranças dos avós, e o inconsciente de sua coletividade, sejam crianças, sejam jovens, e sejam ainda adultos. Tais contos marcaram o imaginário de várias gerações, localidades geográficas e culturais, de forma que, mesmo contemporaneamente, conferem sentido para muitos.

Interessante assinalar que, diante da narrativa performática, todos os ouvintes ficavam com os olhares arregalados e muito atentos a cada impostação de voz, gestos, mímicas e suspiros emitidos pelo narrador. O corpo arrepiava, os olhos visualizam as cenas descritas, e a emoção tomava conta da atmosfera. Nessa perspectiva, Queiroz (2007) afirma que o ritmo, a teatralização e os gestos do contador de histórias produzem um efeito sinérgico que invade a todos, remexendo profundamente a imaginação dos ouvintes.

Nesse particular, parece que a ambiência da comunidade propiciava ou se somava à composição das narrativas, o que, talvez, fosse motivado pela conjuntura da época. Sejam exemplos, a ausência de energia elétrica, das tecnologias de comunicação ou dos brinquedos eletrônicos que pudessem desviar a atenção. A maioria das casas e das famílias não era equipada com televisores. Isso, de certa forma, fazia com que sobrasse tempo para o diálogo, e as narrativas fluíam sem pressa, ao som de corujas, grilos, sapos e cigarras. Parecia que tal ambiência aproximava as pessoas e contribuía para a valorização das narrativas, tornando os sujeitos mais unidos uns aos outros. Notadamente porque valores como respeito, educação, partilha, união e amizade eram sempre lembrados e reiterados nessas reuniões e nas histórias. Os idosos, talvez sem que o soubessem, desempenhavam a função familiar de práxis pedagógica espontânea, pois sempre havia a figura de um deles na posição de contador.

Mas os anos e as décadas se passaram. O que verificamos nos dias atuais, segundo Bosi (2004), é uma atuação forte do universo midiático de informações, tendo como principais suportes a internet, a televisão, o rádio, as revistas, que cotidianamente estão presentes na vida das pessoas. Para acessá-los, basta um "click" na tela do smartfone. Se, por um lado, essas tecnologias ensejaram maior circulação de informação e comunicação entre os 
sujeitos, por outro, na medida em que são utilizadas sem limites, impõem às pessoas um individualismo preocupante. Diante desse cenário, seria pertinente perguntar: as novas tecnologias presentes no cotidiano da modernidade atrapalham as relações sociais dos sujeitos? Será que ainda existe a valorização da função desempenhada pelos contadores de história, na figura do idoso, numa sociedade cada vez mais capitalista e midiática?

As reflexões engendradas por Bosi (1994) sobre a conjuntura da sociedade moderna apontam para uma situação adversa, pois, segundo a autora, a sociedade atual é marcada por hábitos capitalistas ao extremo, em que tudo é descartável, e as informações que nela transitam tornam as pessoas sem tempo e espaço para ouvir o outro. Assim, as famílias vão se afastando das relações de contato cotidiano. São cada vez mais raros os momentos em que participam juntos da convivência coletiva, do almoço e do jantar em família, da conversa do final da tarde, do reunir para ouvir as histórias dos mais velhos, dado que quando retornam do trabalho, da escola, da academia, e de seus afazeres já estão exaustos. Querem somente descansar ou se isolar. Cada um, então, se dirige a seu quarto, acompanhado de seu tablet ou smartfone. Diante desse cenário, o que se percebe, no entender da autora, é um verdadeiro estilhaçamento da coletividade em favor da individualidade.

Esse contexto suscita outra pergunta: como podemos pensar a função dos velhos nesta sociedade capitalista, cada vez mais fragmentada? Bosi (1994) argumenta que os idosos são possuidores de uma memória rica de histórias do vivido, construída no curso de sua existência. Halbwachs (1998) complementa afirmando que os contadores de histórias, ao narrarem, expressam suas lembranças e memórias mais profundas. Para Pollak (1992), os velhos exercem o papel de propiciar continuidade às tradições e valores socioculturais, pois, como guardiões da palavra e da memória, refletem o universo cultural da ambiência em que vivem.

Em relação às narrativas na ambiência de comunidades negras, Hampaté Bâ (2010) e Vansina (2010) também ressaltam a importância dos idosos na sustentação da história do grupo, no qual estes seriam o alicerce e a base onde se reúnem a memória e a enciclopédia da comunidade. Por isso, são considerados os guardiões dessas histórias, com todos os seus sistemas simbólicos de significação. Nesse sentido, este artigo procura responder às seguintes perguntas: na comunidade quilombola de Morrinhos/Poconé-MT, o idoso/a mantém a função de narrador de histórias? Quais as histórias narradas por eles? E qual o ensinamento que se pode extrair dessas narrativas? 
Os argumentos reunidos neste texto estão organizados em cinco partes. Esta introdução, que apresenta a problematização do tema, os objetivos e as perguntas de pesquisa. A segunda parte desfila uma breve descrição da comunidade pesquisada e os procedimentos metodológicos de coleta de dados. Já a terceira discute alguns conceitos importantes sobre tradição oral, lenda e o caráter educativo das narrativas. Por sua vez, a quarta parte descreve três narrativas colhidas na comunidade de Morrinhos, e esboça algumas análises. Por fim, na última parte, são tecidas considerações a respeito do que foi tratado no texto em seu conjunto.

\section{LÓCUS DA PESQUISA E ESCLARECIMENTOS METODOLÓGICOS}

A comunidade de Morrinhos é um território quilombola, localizado na zona rural, às margens do rio Bento Gomes, em Poconé-Mato Grosso, certificado pela Fundação Cultural Palmares em 2015. Trata-se de uma pequena comunidade, onde residem 24 famílias com uma média de quatro moradores por casa. Possui praticamente uma rua principal, cuja extensão é de, no máximo, três quilômetros. Segundo relato de moradores, a comunidade foi fundada há aproximadamente 150 anos. Ainda de acordo com relatos orais de membros da comunidade, foi ela fundada por um casal de descendentes de escravizados que habitavam a região, sendo que as terras foram adquiridas mediante compra.

Em Morrinhos, as residências se distribuem ao longo da rua principal. Algumas casas são de madeira, cobertas com palhas. Outras, de adobe. Bem poucas são feitas de alvenaria, todas bastante simples. Ao longo do trajeto também estão o campo de futebol, a igreja católica e a Escola Municipal de Morrinhos. Cabe registrar que se trata da única escola nas imediações, atendendo os alunos até o quinto ano, de acordo com o sistema multisseriado, período diurno. Na escola também funciona uma sala de Educação de Jovens e Adultos, período noturno.

O relatório antropológico do INCRA (BRASIL, 2014) aponta que 53\% dos moradores são homens, ao passo que $47 \%$ são mulheres. A comunidade vive da agricultura de subsistência. Desenvolve a plantação de banana, milho, abóbora, batata, abacaxi, melancia, somada à criação de animais de pequeno porte, como galinhas, suínos, entre outros. Alguns dos moradores também trabalham em uma mineradora, que se situa na divisa com o território da comunidade. 
Morrinhos, em sua fundação, possuía 650 hectares. Contudo, hoje desse território resta menos que a metade, dado que foi ocupado, ao longo da história, por fazendeiros, tal como aconteceu com a maioria dos quilombos contemporâneos. Todos os moradores são ligados por consanguinidade e parentesco. Nos eventos que ocorrem na comunidade, há participação de todos, com seu sistema de troca, de solidariedade, ocasião em que reúnem seus membros em torno do preparo das várias festas de santo que lá acontecem, ou diante da luta pela posse definitiva da terra. Essas reuniões e confraternizações encerram significativo efeito na manutenção e união do grupo, diante das reivindicações de direitos sociais e políticos a eles historicamente negados (CASTILHO, 2011).

Metodologicamente, a entrevista semiestruturada foi a principal ferramenta utilizada para coletar dados contidos no presente texto, além da observação participante. Foram entrevistados dois anciões: Senhor Heleno e Senhor Gonçalo, residentes da comunidade de Morrinhos e considerados pela coletividade os guardiões da história do grupo. A escolha dos anciões faz referência às considerações de Hampaté Bâ (2010) e Vansina (2010), ao se reportarem ao importante papel dos idosos em comunidades tradicionais africanas, ou afro-brasileiras, na qualidade de guardiões das histórias e de esteio histórico e cultural que sustenta o grupo.

A história oral, para Portelli (2010), tem se mostrado uma ferramenta metodológica social importante nos meios acadêmicos por dar visibilidade àqueles grupos que sempre foram oprimidos, marginalizados e silenciados pela história oficializada. Ademais, tais narrativas, contemporaneamente, têm se mostrado eficazes e pertinentes para o debate social no tocante às concepções de memória e história, reforçando os reflexos dessa relação na vida das pessoas, para além da simples preservação da informação. De igual forma, representam um significado de resistência. Nesse sentido, há muito que conhecer, compreender e aprender sobre os quilombos contemporâneos, assim como sobre os saberes e fazeres culturais de seus habitantes.

As entrevistas foram feitas na residência dos colaboradores, conforme o tempo e a disponibilidade de cada entrevistado. O roteiro de entrevista semiestruturada procurou conhecer as narrativas mais ouvidas/narradas na comunidade, e os sentidos subjacentes a elas. Ou seja, buscou-se explorar o aprendizado que se pode extrair da narrativa contada. Foi assinado também o Termo de Consentimento Livre e Esclarecido, no qual os dois anciões autorizaram a gravação da entrevista, bem como a publicação de suas narrativas. 
A análise das narrativas está calçada na técnica da análise de conteúdo proposta por Bardin (1995), em observância à postura interpretativa encampada por Geertz (2008). Para a primeira autora, a análise de conteúdo busca o recorte e a organização de temas, em torno de enunciados prenhes de significado. Para o segundo autor, o ser humano emana significados adquiridos culturalmente e os reproduz. Fazer essa leitura requer ir além do que os olhos veem. Ou, melhor dizendo, é preciso perceber os aspectos mais sutis que perfazem o discurso sociopolítico-cultural de um povo, de uma comunidade, guardando a sensibilidade de ler, com os sentidos, as narrativas, os saberes e fazeres socioculturais dos sujeitos por meio dos significados que eles atribuem ao vivido.

É importante vincar que são escassos os estudos que se dedicaram à análise, em profundidade, do caráter pedagógico das narrativas orais, especificamente as que ocorrem no espaço-tempo de comunidades quilombolas. Desse modo, este artigo abarca resultados exploratórios, quiçá estimule outras pesquisas que aprimorem as ideias e os conceitos.

\section{A TRADIÇÃO ORAL E O FUNDAMENTO DAS NARRATIVAS ORAIS}

Os seres humanos, ao longo dos tempos, sempre contaram histórias, e suas narrativas espontâneas, reais ou fictícias refletiam a busca de explicação e compreensão da ambiência em que viviam. Nesse contexto, nascem os mitos e as lendas. No enfoque das perspectivas de Krugers (2011), há uma ligeira diferença entre elas. Os mitos se subdividem em três vertentes: a escatológica, que versa sobre o fim dos tempos; a cosmológica, que procura explicar o universo; $\mathrm{e}$ a etiológica, que trabalha a ideia de explicação da ambiência em que os sujeitos estão inseridos. Por outro lado, as lendas são histórias que misturam o real e o fictício. São criadas de forma espontânea e necessitam de um narrador que Ihes dê vida. Portanto, é imprescindível a figura do contador de histórias para adicionar a elas ingredientes pessoais e, assim, reinterpretá-las a cada instante em que são repetidas às novas gerações. Tais narrativas têm em comum o fato de serem permeadas por simbologias, trilhando um enredo que envolve o sobrenatural. Por meio de narrativas orais foi possível criar e recriar grande parte da história da humanidade. Conforme podemos ler em Meihy (2014):

A afirmação corrente diz que a história oral é tão antiga como a própria História, mas isso é vago. Fala-se que toda a história antes de ser escrita passou por etapas narrativas ou manifestações da oralidade aferidas [...] O pilar dessa afirmação é a certeza de que 
tanto a Bíblia como outros livros sagrados, bem como as mitologias fundamentais da cultura ocidental e mesmo os poemas seminais da aventura humana - como a llíada e a Odisseia -, têm origem na oralidade. (MEIHY, 2014, p. 92).

Tradição oral é a expressão que se atribui ao ato de transmissão oral da visão de mundo de um determinado grupo e de sua explicação sobre ele, segundo os mais variados ângulos. Pode ser definida "como um testemunho transmitido verbalmente de uma geração para outra. Suas características particulares são o verbalismo, e sua maneira de transmissão [...] difere das fontes escritas" (VANSINA, 2010, p. 140). Os estudos das tradições orais se preocupam, conforme Meihy (2014) em registrar:

Explicações sobre a origem dos povos; crenças referentes às razões vitais do grupo e ao sentido da existência humana, enquanto experiência que imita a vida; e o comportamento, bem como o destino dos deuses, semideuses, heróis e personagens malditos, fantásticos e históricos são aspectos caros aos estudos das tradições orais. (MEIHY, 2014, p. 41).

Bosi (1994) argumenta que, em comunidades tradicionais, os idosos são tidos como os guardiões da palavra, os narradores-mestres, portanto os responsáveis pela preservação de um tesouro espiritual de apreço para o grupo, por semearem as tradições culturais na ambiência. Conforme Hampaté Bâ (2010), para algumas populações africanas a explicação é que a oralidade surgiu, a partir do momento em que Deus (Maa Ngala), ao fazer a natureza incompleta, criou o homem (Maa) para dar continuação à sua obra, e aperfeiçoá-la. Mas, para que isso sucedesse, houve necessidade de criar, entre ambos, uma forma de comunicação. Nesse cenário é que surge a palavra, fruto da ponte dialógica entre o homem e os deuses, a qual se deu pelo sopro divino. A palavra, de divina, se tornou, então, sagrada.

Para o mesmo autor, a tradição oral se baseia em certa concepção de homem, do seu lugar e do seu papel no seio do universo. Nesse panorama, a sociedade ancestral negra é considerada uma das referências nesta tradição, em que histórias, contos, lendas, mitos e rituais são criados, narrados e compartilhados por avós, pais, filhos e todos da coletividade social. Afinal, no princípio, constituía uma sociedade eminentemente da palavra falada - ágrafa -, e os Griots e/ou Maa Ngala eram pessoas detentoras da arte da palavra, na tradição africana. Nesse contexto, encontrava-se na expressão dos anciões o poder de preservar a essência da sabedoria do povo, como riqueza cultural dos antepassados (HAMPATÉ BÂ, 2010, p. 183). 
No pensar de Vansina (2010):

Uma sociedade oral reconhece a fala não apenas como um meio de comunicação diária, mas também como um meio de preservação da sabedoria dos ancestrais, venerada no que poderíamos chamar elocuções-chave, isto é, a tradição oral. [...] Quase em toda parte, a palavra tem um poder misterioso, pois palavras criam coisas. Isso, pelo menos, é o que prevalece na maioria das civilizações africanas. (VANSINA, 2010, p. 139-140).

A importância dada tanto pela sociedade africana quanto pela afrodescendente à linguagem falada está no reconhecimento de que o ser humano é a sua palavra, portanto é a voz que o seguirá por gerações e, uma vez pronunciada, não retorna. As palavras se inscrevem, pois, como as águas de um córrego que, ao passar por determinado ponto, não retroagem, antes seguem em frente. De modo similar, para a cultura africana, isso funciona com a palavra dita, que ecoa em vozes refletidas nos filhos, netos, amigos, companheiros e parentes que partilham das mesmas tradições. Um pouco daquilo que Márquez (2003) expressou:"A vida não é o que a gente viveu, e sim o que a gente recorda e como recorda para contá-la" (MÁRQUEZ, 2003, p.5).

Como já fora mencionado, comunidades tradicionais, a exemplo de Morrinhos, lócus desta pesquisa, têm na oralidade uma dimensão importante das significações de sua vida e vivência. Os trabalhos dos tradicionalistas Hampaté Bâ (2010) e Vansina (2010) demonstram que, de acordo com a concepção dos praticantes africanos da Tradição Oral, o ser humano é resultado de seu discurso, porquanto, para essas sociedades, a fala foi recebida dos deuses, portanto, trata-se de algo divino. E, revelando-se sagrada para o homem, os guardiões da palavra, como são chamados os anciões e anciães, são em extremo importantes nesses grupos. Em outras palavras: na medida em que um ancião fala, ou narra a palavra, carrega consigo toda a força da ancestralidade de seu povo (HAMPATÉ BÂ, 2010), ao passo que a falta ocasionada pela morte de um deles é tida como uma enciclopédia que se queima.

A tradição oral é reconhecida pelos estudiosos do tema como um lugar: espaço e tempo de construção e partilha de conhecimentos e sociabilidades. Na concepção de Hampaté Bâ (2010), os mestres tradicionalistas - ou seja, os grandes depositários da herança oral, na tradição Africana -, eram nomeados de diversas maneiras, segundo a região. No entanto, o sentido se resumia em "fazedores do conhecimento", ou simplesmente "conhecedores", 
ou mestres de iniciação de um ramo profissional. O que transmitiam era a "ciência da vida" - "trata-se de uma ciência eminentemente prática que consiste em saber como entrar em relação apropriada com as forças que sustentam o mundo visível e que podem ser colocadas a serviço da vida" (HAMPATÉ BÂ, 2010, p. 175).

Essa forma de educação se constrói espontaneamente e cotidianamente:

"[...] no seio de cada família, onde o pai, a mãe ou as pessoas mais idosas são ao mesmo tempo mestres e educadores e constituem a primeira célula dos tradicionalistas. São eles que ministram as primeiras lições da vida, não somente através da experiência, mas também por meio de histórias, fábulas, lendas, máximas, adágios, etc. (HAMPATÉ BÂ, 2010, p. 183).

O ato da narração se reveste, portanto, de um caráter eminentemente pedagógico, por envolver conhecimento que, por sua vez, remete ao ensino-aprendizagem que permeia esse espaço-tempo. Ousamos afirmar que essa pedagogia se inclui na categoria de pedagogia espontânea ou natural, compreendida como as aprendizagens construídas fora de instâncias institucionais, na ambiência familiar, por meio de reuniões também espontâneas. Como didática, destacam a observação e a audição das narrativas, em que se aprendem coisas da vida, os valores, as crenças, os costumes, como também o respeito, a união, a amizade, a solidariedade, entre outros. Isso tudo sem que haja alguém especialmente designado para ensinar, ou que exista intenção deliberada e consciente para aprender.

O aprendizado se constrói no âmbito das famílias, nos quintais, na festa, na pescaria, no mutirão, no velório, na lavoura. Especificamente para os quilombolas, as narrativas orais são acrescidas de elementos simbólicos, compreendidas como atividades de natureza lúdica, partícipe e grupal. Nesse contexto, há interação entre as narrativas, os narradores e a territorialidade, o parentesco, o compadrio, a vizinhança (XIMENES, 2001). A criação e manutenção de laços afetivos se caracterizam tão essenciais quanto o que pode ser aprendido nesses espaços-tempo.

As tradições da cultura oral nessas comunidades se manifestam em diferentes gêneros de suas narrativas, refletindo em saberes e fazeres espontâneos reproduzidos no dia a dia comunitário, em um processo contínuo, transmitido às novas gerações e, assim, garante-se a preservação da identidade cultural do grupo. 
4. ANÁLISE dE TRÊS LENDAS NARRADAS PELOS ANCIÕES DA COMUNIDADE QUILOMBOLA DE MORRINHOS/POCONÉ-MT

Segundo Siqueira (2002) e Leite (1995), inúmeras narrativas compõem o imaginário coletivo do povo de Mato Grosso, desde a sua fundação. São histórias contadas de "boca em boca", que se propagam por meio de gerações afora, tornando-se contos populares. Possuem ingredientes típicos de expressões orais, posto que sempre necessitam de um contador para que elas se tornem vivas na memória e na cultura do povo.

A comunidade quilombola de Morrinhos, tal como se dá com outras cidades da região mato-grossense, partilha inúmeras narrativas, embora cada região resguarde sua própria versão, incluindo maneiras diferentes de interpretação, que variam de acordo com a localidade onde é narrada, e com as características da região. Por exemplo: "A Alavanca de Ouro" ou "Martelinho de Ouro", narrados em regiões auríferas, "O Minhocão”, próprio de região ribeirinha, e "O Lobisomem", narrado em comunidades rurais, de modo geral.

Como foi mencionada em páginas precedentes, a tradição oral é rica em variedade de narrativas, sendo mais conhecidas o mito e a lenda. Neste texto, analisaremos três lendas narradas por dois anciões: Sr. Gonçalo e Sr. Heleno, ambos da comunidade de Morrinhos. Conceitualmente, a lenda é uma narrativa inerente à coletividade e tenta dar explicações sobre alguns elementos ou fenômenos da natureza, ao mesmo tempo em que apresenta uma experiência de vida, indutora de reflexões, prevalecendo uma moral e/ ou um ensinamento (JESUS; BRANDÃO, 2003).

\section{O Minhocão}

Quando nós morávamos ali em cima, nos tinha dois poço, um por nome de poço redondo. O poço redondo, quando secava, ficava uma correnteza até que cortava. Nesse poço, fazia redemoinho, assim, quando às vezes que tinha às vezes que gente chegava lá, parecia que ele tinha aquele rumor, revirava tudo aquele poço. Parecia que revirava aquele poço, por outro lado nos via lá tipo de uma canoa debruço, então, nós acreditávamos que podia ser o minhocão, porque na água, falam que tem o bicho mais feroz do que no seco. Eu vou falar pro senhor, quando eu era novo, pra mim não tinha rio cheio pra mim atravessa, eu tirava minha roupa e amarrava na cabeça e oiá, nadava [...], mas de noite, de noite que os bichos saem tem oportunidade de sair e andar... tem muitos que falam que tem uma assombração, esse aí é coisa de outro mundo. (Sr. Gonçalo, 2016). 
A narrativa "O Minhocão" tem como ambiência o espaço sociocultural do pescador e do ribeirinho. Ocorre em várias regiões do Estado de Mato Grosso e do Brasil, em diferentes versões. É marcada também pela presença do indivíduo narrador, conhecedor profundo da natureza onde vive e de seus mistérios, podendo imprimir seu próprio tom à narrativa. Do ponto de vista da metáfora -"a mais expressiva forma de linguagem para apreender e explicar a realidade" (JESUS; BRANDÃO, 2003) - reflete o desejo de dar, à maneira do narrador, explicação ao fenômeno natural. Nesse caso, ao redemoinho que ocorre dentro dos rios e lagos.

Mas o elemento mais significativo, merecedor de ênfase da parte do narrador, por meio da elevação e impostação da voz, diz respeito à advertência que deseja transmitir aos ouvintes, em especial àqueles que têm por hábito desobedecer à regra de não abusar do banho de rio durante o dia e evitar banhar-se nele durante a noite. Dessa forma, a narrativa contribui para disciplinar e/ou normatizar a relação do homem com a natureza, mais especificamente com o rio.

O Sr. Heleno nos expõe a seguinte narrativa:

\section{"A Bola de Fogo" de Morrinhos}

Meu menino mesmo aqui, o Benedito, quando era solteiro, morava aqui, no início da Vila e o meu concunhado morava lá no final da rua, na última casa, um certo dia, ele tava peloteando passarinho aí na mata, quando apareceu pra ele uma bola de fogo, e ele foi peloteando a bola de fogo, e a bola foi crescendo, quanto mais ele peloteava mais a bola de fogo crescia na direção dele, aí ele começou a correr pra pegar a bola de fogo, mas aí, as meninas irmãs dele, não deixou correr mais atrás da bola de fogo, e puxou ele, e pegou ele, pois é como diz o ditado, né? Agente, está por conta, né? Aí fomos perguntar para os mais experientes, os mais velhos daqui da comunidade, o que significava o que tinha acontecido, né? Sobre a bola de fogo, né. Aí os mais velhos disseram que ele não devia ter peloteado a bola de fogo, porque aquela era a fortuna dele, né, foi isso que sucedeu! (Sr. Heleno, 2016).

A aparição do "Martelinho de ouro" e das "Bolas de Fogo", que sobrevoam e atravessam as madrugadas, ocorre também em várias regiões do Brasil, com significados variantes. Em Morrinhos, acredita-se que a Bola, ou o Martelinho, procura um sortudo que será o beneficiado pela fortuna do ouro, caso tenha coragem de seguir o objeto incandescente. É uma 
narrativa simbólica que carrega significados perpetuados culturalmente por determinadas comunidades, localizadas em regiões em que existe ouro, tais como Cuiabá, Cangas e Morrinhos. Segundo a interpretação do narrador, a pessoa escolhida precisa ser corajosa o suficiente para seguir a "luz" e desenterrar a herança.

Não bastasse, passa-se o ensinamento de que não se deve pelotear - atirar pedras com estilingue - em passarinho. As crianças e jovens, que habitam áreas rurais, costumam cultivar o lazer de matar passarinho nas matas, infringindo maus tratos a ele. Algumas vezes, a depender da ave, ela é servida para refeição da família. Outras vezes, ela é simplesmente morta e descartada. Os pais, é preciso dizê-lo, discordam veementemente dessa prática. Em razão disso, possivelmente a narrativa traz embutida a advertência de não sair pela mata, apedrejando passarinho, visto que a Bola de Fogo pode aparecer... Embora nessa versão a mensagem da Bola seja positiva, não se deve esquecer que ela amedronta e atemoriza.

Outra lenda bastante comum na ruralidade, que integra o imaginário coletivo em Morrinhos, é a do "Lobisomem", ao modo como fora narrada pelo ancião senhor Gonçalo:

\section{O Lobisomem}

O senhor já ouviu falar sobre a localidade de Boa Vista, pois é lá tinha um sujeito que era o retrato de lobisomem, ele mesmo dizia que era um. $\mathrm{O}$ nome dele era Venâncio e a mãe dele chamava Cutá. Ele era feio pra burro. Certo dia, numa noite de lua cheia, a mãe dele disse filho vamos no sítio de Benedito, mas a meio caminho, Venâncio falou pra mãe dele, que precisa ir ao mato pra fazer "precisão" [necessidades fisiológicas], enquanto a mãe aguardava, começou a ouvir alguns uivos e barulhos estranhos, quando de repente, apareceu o bicho e desandou correr atrás dela, chegando a rasgar a saia dela, mas ela graças ao bom Deus conseguiu escapar. Aí, seu mano, o povo descobriu que o Venâncio era mesmo o lobisomem. Dias depois, ele começou espalhar por aí, que lembrava que tinha corrido atrás da mãe dele, e ela corria mais ainda. Eh, seu mano, Deus fez o dia pra nós seu mano, e a noite que é a treva pra os bichos. (Sr. Gonçalo, 2016).

A narrativa "O Lobisomem" é conhecida universalmente. Segundo estudiosos do tema, essa lenda nos foi trazida pelos europeus. Encarta variadas versões e interpretações, mas a mensagem advinda dela, que paira no imaginário coletivo da comunidade de Morrinhos, é que, a partir de determinado horário, as pessoas da comunidade devem se recolher em suas 
casas, para evitar o ataque dos bichos. Comprovam-no as palavras do ancião Sr. Gonçalo: "Deus fez o dia pra nós e a noite, que é a treva, para os bichos". "A noite é para descanso, ficar recolhido [...] nós devemos respeitar a natureza."

Tais histórias expressam aquilo que Hampaté Bâ (2010), assim como Munanga (2005), considera a propósito do papel das narrativas no sentido abrangente: falam de história, constituem a identidade profunda da comunidade, são uma arte (MUNANGA, 2005, p. 85). O ato de narrar produz efeitos também múltiplos: valoriza a sabedoria do idoso, potencializa sua autoestima e sua autoconfiança como detentor de certo capital cultural. Por outro lado, Silva (2011, p. 34) afirma que: "Na medida em que essa cultura tem valor em termos sociais, [...] na medida em que ela faz com que a pessoa que a possui obtenha vantagens materiais e simbólicas, ela se constitui como capital cultural". Além disso, estimula o intelecto do narrador, pois ele interfere, cria e recria os acontecimentos narrados com uma riqueza de detalhes sui generis, abarcando a ideia difundida de que "quem conta um conto aumenta um ponto". Nesse sentido, as narrativas têm um sentido pedagógico espontâneo (VANSINA, 2010).

Por outro lado, promovem a (re)construção da sabedoria do grupo, dado que "os saberes e fazeres culturais moldam os sujeitos condicionando-os, e as tradições são impregnadas de saberes e fazeres culturais, que têm na narrativa uma das formas de manifestação" (VANSINA, 2010, p.141), além de potencializar a sociabilidade e a união das famílias e da comunidade.

Não há narrativas inúteis e/ou desinteressadas. Pode-se verificar que os significados trazidos pelas narrativas míticas guardam a função de demonstrar a dramatização ritualística simbólica da gênese humana para dar explicação à razão existencial de sua espécie e assim responder às angústias que permeiam as dimensões socioculturais dos seres humanos, porquanto a visão de cada cultura sobre tais explicações a respeito do sobrenatural influencia o modus vivendi dos sujeitos nas comunidades (CUCHE, 1999).

\section{Considerações FINAIS}

Narrar histórias é uma arte, e não é qualquer pessoa que consegue desempenhar com mestria tal tarefa. Os anciões, na visão de Hampaté Bâ (2010) e Vansina (2010), são pessoas especiais, escolhidas de forma espontânea no coletivo social, para transmitir com entusiasmo as tradições e conteúdos da memória coletiva do/ao grupo, bem como para repassar os ensinamentos 
necessários que visam à boa convivência com a natureza e com as pessoas com as quais se relacionam.

Nesse sentido, foi possível perceber que os dois anciões de Morrinhos, lócus desta pesquisa, conservam em suas memórias variadas narrativas e exercem alegremente o papel de narradores. Eles sentem-se importantes ao contar suas histórias nas rodas de conversa, lembrando o que afirmou Meihy (2014, p.83): "além de outros efeitos, [narrar] propicia aos idosos a conquista da dignidade e da autoconfiança". Na comunidade, a relação existente entre os idosos e as novas gerações ainda é de respeito e de profunda consideração. Eles continuam ocupando o lugar de esteio, guardiões da história do grupo.

Vivem em uma dimensão que contraria a condição de apagamento que muitos velhos vivenciam, na atualidade. Bosi (1994), por exemplo, argumenta que os idosos, na maioria das vezes, não são ouvidos pela sociedade contemporânea, particularmente pelos mais jovens. Embora já tenham desempenhado suas funções produtivas na sociedade, ainda são portadores de fatos vividos e experiências importantes para serem compartilhados. Esse não reconhecimento contribui para o empobrecimento das relações sociais travadas no cotidiano das famílias e das sociedades, especialmente entre as gerações.

Quanto às suas narrativas, percebe-se que são do tipo lendas e carregam releituras próprias e interpretação. No geral, trazem consigo um ensinamento, ou seja, uma dimensão pedagógica, que chamamos aqui de Pedagogia espontânea ou natural, no sentido de que as reuniões das famílias, parentes, vizinhos ou amigos são sempre espontâneas e, da mesma forma, se inicia a contação das histórias. Os jovens, ao ouvirem, passam a respeitar as matas, os animais, os rios e lagos. Da mesma forma aprendem a não desobedecer aos mais velhos. Os narradores não sabem que estão ensinando, e os ouvintes que estão aprendendo. E nós, os espectadores, ouvimos as narrativas com respeito, carinho e atenção, curiosos para saber sobre o desfecho de cada história.

O intuito maior deste artigo, ao versar sobre as narrativas, foi dar visibilidade aos fazeres e saberes culturais da comunidade quilombola Morrinhos, na dimensão da oralidade, como um processo de pedagogia cultural popular, integrante de nossa cultura. Carregam imaginários que compõem nossa brasilidade e, consequentemente, fazem parte do patrimônio da humanidade. Daí a importância de as revalorizarmos como preciosas fontes literárias a serem reconhecidas pelas escolas, ultrapassando os limites das narrativas míticas eurocêntricas, que ainda estão presentes, em maior quantidade, nos 
conteúdos curriculares, principalmente no material didático e paradidático das escolas. Em adendo, é de considerar que estimulam a imaginação, elemento fundamental no processo de aprendizagem.

\section{THE EDUCATIONAL CHARACTER OF ORAL NARRATIVES GIVEN BY ELDERLY MEMBERS OF THE MORRINHOS QUILOMBOLA/POCONÉ-MT COMMUNITY}

ABSTRACT: The aim of this article is to establish the relation between the oral narratives heard in the the Morrinhos quilombola community, situated in the municipality of Poconé, State of Mato Grosso, and the educational processes built through them within the family environment. The methodology used was the oral history, and the instrument used for collection of information was the interview. For theory, the article is supported on Bosi (2004), Vansina (2010), Hampaté Bà (2010), and Meihy (2014), among others. The results show that the elderly still play an important part in the preservation of this community's memory by contributing to the (re)construction of essential meanings for the sociocultural constitutions of subjects, more specifically, reinforcing values in children and young people, such as respect for nature and obedience to older people.

KEYwoRDS: Education. Quilombo. Oral tradition. Spontaneous pedagogy.

\section{EL CARÁCTER EDUCATIVO DE LAS NARRATIVAS ORALES DE LOS ANCIANOS DE LA COMUNIDAD QUILOMBOLA MORRINHOS/POCONÉ- MT}

RESUMEN: El objetivo de este artículo es establecer la relación entre las narrativas orales de la comunidad quilombola de Morrinhos, ubicada en el municipio Poconé, Estado de Mato Grosso y los procesos educativos que son construidos a través de ellas en el ambiente familiar. La metodologia utilizada fue la narrativa oral y el principal instrumento de colecta de informaciones fue la entrevista. Teóricamente, el artículo se apoya en Bosi (2004), Vansina (2010), Hampaté Bâ (2010) y Meihy (2014), entre otros. Los resultados señalan que los ancianos todavía desempeñan una función importante en la preservación de la memoria de esa comunidad, contribuyendo para la (re) construcción de significados esenciales para el proceso de constitución sociocultural de los sujetos, específicamente, reforzando los valores en los niños y jóvenes, tales como el respeto a la naturaleza y la obediencia a los más viejos.

Palabras-Clave: Educación. Quilombo. Tradición oral. Pedagogía espontánea. 


\section{REFERÊNCIAS}

BARDIN, L. Análise de conteúdo. Lisboa: Edições 70, 1995.

BOSI, E. Memória e sociedade: lembranças de velhos. 3. ed. São Paulo: Companhia das Letras, 1994.

. Memória e sociedade. 13. ed. São Paulo: Companhia das Letras, 2004.

BRASIL. INCRA. Relatório antropológico de caracterização histórica, econômica, ambiental e sociocultural, da CRQ Morrinhos. Poconé. Mato Grosso [s.d.].

CASTILHO, S. D. Quilombo contemporâneo: educação, família e cultura. Cuiabá: EdUFMT, 2011.

CUCHE, D. A noção de cultura nas ciências sociais. Bauru: Edusc, 1999.

GEERTZ, C. Interpretação das culturas. LTC Livros técnicos e científicos. Rio de Janeiro: Editora S.A., 2008.

O saber local: novos ensaios em antropologia interpretativa. Petrópolis, RJ: Vozes, 1997.

HALBAWCHS, M. A memória coletiva. São Paulo: Vértice, 1998.

HAMPATÉ BÂ, A. A tradição viva. In: Ki Zerbo, (org.). História geral da África l: metodologia e pré-história da África / editado por Joseph Ki-Zerbo. - 2. ed. rev. Brasília: UNESCO, 2010. p.167-212.

JESUS, L. M.; BRANDÃO, H.N. Mito e tradição indígena. In: BRANDÃO, H, N. (Org.). Gênero e discurso na escola: mito, conto, cordel, discurso político, divulgação científica. São Paulo: Cortez, 2003.

KRUGER, M.F. Amazônia mito e literatura. 3. ed. Manaus: Editora Valer, 2011.

LEITE, M. C. S. A poética do sobrenatural no homem ribeirinho: o minhocão. São Paulo: FFLCH/USP, 1995. Mimeo.

MÁRQUEZ, G. G. Viver para contar. Rio de Janeiro: Record, 2003.

MEIHY, J. C. S. B. História oral: como fazer, como pensar. 2. ed. São Paulo: Contexto, 2014.

MUNANGA, K. (Org.). Superando o racismo na escola. Brasília-DF: Ministério da Educação. Secretaria de Educação Continuada, Alfabetização e Diversidade, 2005.

POLLAK, M. Memória e identidade social. Estudos Históricos, Rio de Janeiro, v. 5, n. 10, 1992.

PORTELLI, A. Ensaios de História Oral. São Paulo: Letra e Voz, 2010.

QUEIROZ, A. de O. As inscrituras do verbo: dizibilidades performáticas da palavra poética africana. 2007. 310 f. Tese (doutorado em Teoria da Literatura)-Universidade Federal de Pernambuco, 2007. 
SILVA, T. T. D. Documentos de identidade. Uma introdução às teorias do currículo. Belo Horizonte: Autêntica, 2011.

SIQUEIRA. E. M. História de Mato Grosso. Da ancestralidade aos dias atuais. Cuiabá: Entrelinhas, 2002.

VANSINA, J. A tradição oral e sua metodologia. In: Ki Zerbo. (Org.). História geral da África I: metodologia e pré-história da África / editado por Joseph Ki-Zerbo. 2. ed. rev. Brasília: UNESCO, 2010. p. 139-166.

XIMENES, T. M. Educação e violência: a produção da demanda para a educação não-formal. In: SIMSON, O. R. M. V; PARK, M. B.; FERNANDES, R. S. (Org.). Educação não-formal: cenários da criação. Campinas, SP: Editora UNICAMP/CMU, 2001. p. 41-58.

Suely DulCe de CAstillho: Doutora em Educação e Currículo pela PUC/SP, Professora do Departamento de Teoria e Fundamentos da Educação e do Programa de Pós-Graduação em Educação, linha de pesquisa Movimentos Sociais e Educação da Universidade Federal de Mato Grosso. Pesquisadora sobre Quilombos contemporâneos e culturas afro-brasileiras.

E-mail: castilho.suely@smail.com

Jocimar Jesus Campos: Mestrando no Programa de Pós-Graduação em Educação da Univerdidade Federal de Mato Grosso (PPGE/UFMT). Atualmente é Professor de Educação Básica da Secretaria de Estado de Educação do Estado do Mato Grosso. Tem experiência na área de Letras, com ênfase em Língua Portuguesa.

E-mail: jocimar_10@yahoo.com.br 
